\title{
Long-Term Outcomes of Single-Vessel Percutaneous Coronary Intervention on Culprit Vessel vs. Multivessel Percutaneous Coronary Intervention in Non-ST-Segment Elevation Acute Coronary Syndrome Patients With Multivessel Coronary Artery Disease
}

\author{
Tianyu Li, MD; Sida Jia, MD; Yue Liu, MD; Yi Yao, MD; \\ Ying Song, MD; Xiaofang Tang, MD; Xueyan Zhao, MD; Runlin Gao, MD; \\ Yuejin Yang, MD; Bo Xu; Zhan Gao, MD; Jinqing Yuan, MD
}

\begin{abstract}
Background: The optimal percutaneous coronary intervention (PCI) strategy for multivessel lesions in the setting of non-ST-segment elevation acute coronary syndrome (NSTE-ACS) remains controversial. This study sought to compare long-term prognosis between single-vessel $\mathrm{PCl}(\mathrm{SV}-\mathrm{PCl})$ and multivessel $\mathrm{PCl}(\mathrm{MV}-\mathrm{PCl})$ in patients with multivessel coronary artery disease (MV-CAD) presenting with NSTE-ACS in a real-world population.
\end{abstract}

Methods and Results: NSTE-ACS patients with MV-CAD undergoing PCI in Fuwai Hospital in 2013 were consecutively enrolled. $\mathrm{SV}-\mathrm{PCl}$ was defined as targeting only the culprit vessel, whereas MV-PCI was defined as treating $\geq 1$ coronary artery(s) in addition to the culprit vessel at the index procedure. The primary endpoint was the incidence of major adverse cardiovascular and cerebrovascular events (MACCE) at 2 years, consisting of all-cause death, cardiac death, myocardial infarction, unplanned revascularization, or stroke. A total of 3,338 patients were included. Both SV-PCl and MV-PCl were performed in 2,259 patients and 1,079 patients, respectively. During a median follow up of 2.1 years, the MACCE rates and adjusted risk were not significantly different between the SV-PCl and MV-PCl groups (13.1\% vs. $14.0 \%, \mathrm{P}=0.735$; adjusted $\mathrm{HR}=0.967,95 \% \mathrm{Cl}$ : $0.792-1.180$ ). Similar results were observed in propensity-score matching and inverse probability of treatment weighting analyses. Subgroup analysis revealed a consistent effect on 2-year MACCE across different subgroups.

Conclusions: In NSTE-ACS patients with MV-CAD, MV-PCI is not superior to SV-PCI in terms of long-term MACCE.

Key Words: Multivessel percutenous coronary intervention; Non-ST-segment elevation acute coronary syndrome; Percutaneous coronary intervention strategy

$\mathbf{P}$ ercutaneous coronary intervention (PCI) has become a standard of treatment for patients with non-STsegment elevation acute coronary syndrome (NSTEACS). ${ }^{1-3}$ Among patients with obstructive coronary artery disease (CAD), 21-58\% have multivessel CAD (MVCAD). ${ }^{48}$ There is evidence suggesting that incomplete revascularization has a negative effect on long-term outcomes. ${ }^{9}$ Nevertheless, multivessel PCI (MV-PCI) is associated with higher risk of procedure-related complications, which may affect its efficacy and safety. ${ }^{10}$ Thus, there remains a need to find the optimal PCI strategy for those patients to make a trade-off between minimizing the adverse events related to MV-PCI and maximizing the long-term benefits.

The application of different PCI strategies (i.e., culpritonly vs. multivessel) varies among different institutions in everyday clinical practice. The current American and European guidelines recommend considering MV-PCI (Class IIb, B), ${ }^{1}$ or to tailor the PCI strategy to the clinical status, comorbidities, and the disease severity, analogous to the principles of stable CAD (SCAD), ${ }^{3}$ because of lacking evidence from randomized control trials. Results from

Received April 20, 2020; revised manuscript received August 26, 2020; accepted October 29, 2020; J-STAGE Advance Publication released online January 9, 2021 Time for primary review: 44 days

Department of Cardiology, Fuwai Hospital, National Center for Cardiovascular Diseases, Chinese Academy of Medical Sciences and Peking Union Medical College, Beijing, People's Republic of China

The first two authors contributed equally to this work (T.L., S.J.).

Mailing address: Jinqing Yuan, MD, Fuwai Hospital, National Center for Cardiovascular Diseases, Chinese Academy of Medical Sciences and Peking Union Medical College, No.167, North Lishi Road, Xicheng District, Beijing 100037, People's Republic of China. E-mail: dr_jinqingyuan@sina.com

All rights are reserved to the Japanese Circulation Society. For permissions, please e-mail: cj@j-circ.or.jp

ISSN-1346-9843 
10,724 patients underwent $\mathrm{PCl}$ from January 2013 to December 2013

Excluded Patients:

(1) Patients with STEMI $(n=1,445)$

(2) Patients with SCAD $(n=4,295)$

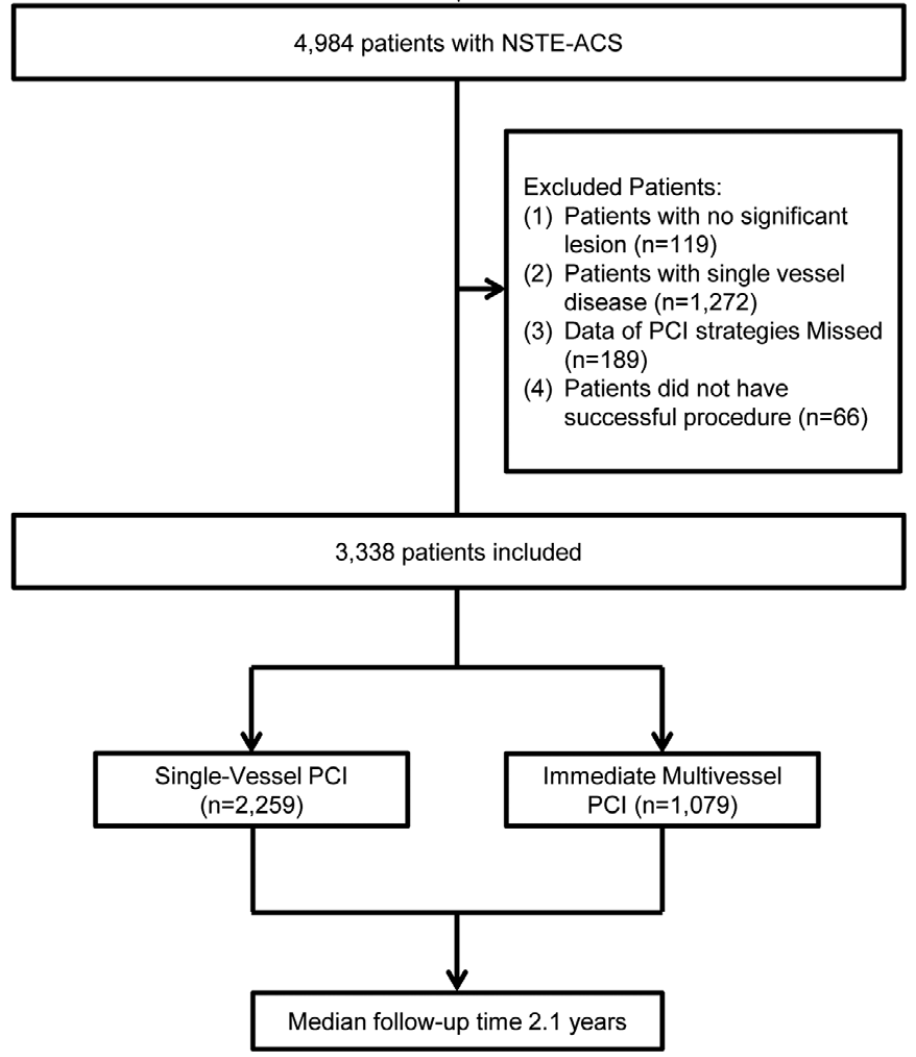

Figure 1. A flow chart for subject selection. PCI, percutaneous coronary intervention; STEMI, STsegment elevation myocardial Infarction; SCAD, stable coronary artery disease; NSTE-ACS, non-STsegment elevation acute coronary syndrome.

previous cohort studies have been inconsistent, with some reporting no significant difference in long-term outcomes between the groups,, $\mathbf{8 1 1 - 1 3}$ some reporting reduced repeat revascularization after MV-PCI,,14-16 whereas others have reported lower mortality with MV-PCI.,6,17,18 Therefore, we aimed to compare long-term prognosis between singlevessel PCI (SV-PCI) and MV-PCI in patients with MVCAD presenting with NSTE-ACS.

\section{Methods}

\section{Study Population}

Data of 10,724 consecutive patients from a single center (Fuwai Hospital, Beijing, China) undergoing PCI from January 2013 to December 2013 were consecutively collected. Although some NSTE-ACS patients with MV-CAD underwent $\mathrm{CABG}$ in our hospital, here we only focused those who underwent PCI in the current analysis. Among them, 3,338 patients with NSTE-ACS and MV-CAD were enrolled after excluding patients with ST-segment elevation acute myocardial infarction (STEMI) $(n=1,445)$, SCAD $(n=4,295)$, no significant lesion $(n=119)$ or single-vessel disease $(n=1,272)$, those whose data for the PCI strategy were missing $(n=189)$, as well as those who did not have successful procedures $(n=66)$ (Figure 1). MV-CAD was defined as having angiographically significant stenosis $(\geq 50 \%)$ in at least 2 major epicardial coronary arteries or their branches, with or without involvement of the left main artery. Successful procedure was defined as an angiographically residual stenosis $\leq 30 \%$ with Thrombolysis in Myocardial Infarction (TIMI) grade 3 flow. None of the involved patients had cardiogenic shock, a glomerular filtration rate $<30 \mathrm{~mL} / \mathrm{min} / 1.73 \mathrm{~m}^{2}$, or received prior coronary artery bypass grafting. The Institutional Review Board approved the study protocol. All patients provided written informed consent before the intervention.

All procedures and medications were performed or managed according to current standard practice guidelines. The choice between SV-PCI and MV-PCI was at the operators' discretion based on each patient's clinical status and comorbidities, as well as the disease severity. SV-PCI was defined as targeting only the culprit vessel, whereas MV-PCI was defined as treating $\geq 1$ coronary artery(s) in addition to the culprit vessel at the index procedure. The 


\begin{tabular}{|c|c|c|c|c|c|c|}
\hline \multirow[b]{2}{*}{ Characteristics } & \multicolumn{3}{|c|}{ All patients $(n=3,338)$} & \multicolumn{3}{|c|}{ Matched patients $(n=1,576)$} \\
\hline & $\begin{array}{c}\text { SV-PCI } \\
(n=2,259)\end{array}$ & $\begin{array}{c}\text { MV-PCI } \\
(n=1,079)\end{array}$ & $P$ value & $\begin{array}{l}\text { SV-PCI } \\
(n=788)\end{array}$ & $\begin{array}{l}\text { MV-PCI } \\
(n=788)\end{array}$ & $P$ value \\
\hline Age, ${ }^{A, B}$ years & $59.7 \pm 9.9$ & $59.3 \pm 10.1$ & 0.2947 & $59.1 \pm 9.9$ & $59.1 \pm 10.1$ & 0.9099 \\
\hline Female, ${ }^{\mathrm{A}, \mathrm{B}}$ n (\%) & $594(26.3)$ & $267(24.7)$ & 0.3385 & $167(21.2)$ & $167(21.2)$ & 1.0000 \\
\hline Body mass index, ${ }^{A, B} \mathbf{k g} / \mathbf{m}^{2}$ & $25.8 \pm 3.1$ & $26.1 \pm 3.4$ & $0.0203^{*}$ & $26.2 \pm 3.1$ & $25.9 \pm 3.1$ & 0.0877 \\
\hline NSTEMI,A n (\%) & $218(9.7)$ & $136(12.6)$ & $0.0095^{\star}$ & $71(9.0)$ & $98(12.4)$ & $0.0279^{*}$ \\
\hline \multicolumn{7}{|l|}{ Risk factors, n (\%) } \\
\hline Current smoker ${ }^{\mathrm{A}, \mathrm{B}}$ & $1,281(56.7)$ & $590(54.7)$ & 0.2699 & $461(58.5)$ & $456(57.9)$ & 0.7985 \\
\hline Diabetes $^{B}$ & 749 (33.2) & $348(32.3)$ & 0.6029 & $246(31.2)$ & $257(32.6)$ & 0.5522 \\
\hline Hypertension ${ }^{B}$ & $1,557(68.9)$ & 747 (69.2) & 0.8579 & $560(71.1)$ & $540(68.5)$ & 0.2725 \\
\hline Hyperlipidemia ${ }^{B}$ & $1,530(67.7)$ & $728(67.5)$ & 0.8810 & $526(66.8)$ & $535(67.9)$ & 0.6288 \\
\hline \multicolumn{7}{|l|}{ Medical history, n (\%) } \\
\hline Prior myocardial infarction ${ }^{B}$ & $339(15.0)$ & $182(16.9)$ & 0.1659 & $133(16.9)$ & $139(17.6)$ & 0.6892 \\
\hline Prior stroke $\mathrm{A}^{\mathrm{A}, \mathrm{B}}$ & $284(12.6)$ & $142(13.2)$ & 0.6337 & $105(13.3)$ & $104(13.2)$ & 0.9408 \\
\hline Prior $\mathrm{PCl} A, \mathrm{~B}$ & $503(22.3)$ & $175(16.2)$ & $<0.0001^{*}$ & $149(18.9)$ & $151(19.2)$ & 0.8979 \\
\hline \multicolumn{7}{|l|}{ Laboratory tests before $\mathrm{PCI}$} \\
\hline Leukocyte, $\times 10^{9} / \mathrm{L}$ & $6.8 \pm 1.8$ & $6.8 \pm 1.8$ & 0.1580 & $6.8 \pm 1.8$ & $6.9 \pm 1.9$ & 0.0986 \\
\hline Platelet, $\times 10 \% / \mathrm{L}$ & $204.8 \pm 54.3$ & $205.4 \pm 51.7$ & 0.7594 & $202.2 \pm 52.2$ & $205.6 \pm 52.2$ & 0.1919 \\
\hline Hemoglobin, g/L & $142.3 \pm 15.5$ & $141.7 \pm 15.5$ & 0.2516 & $143.9 \pm 14.9$ & $142.2 \pm 15.4$ & 0.0326 \\
\hline Creatinine, $\mu \mathrm{mol} / \mathrm{L}$ & $75.3 \pm 16.4$ & $75.0 \pm 15.3$ & 0.6297 & $75.7 \pm 16.5$ & $75.8 \pm 15.0$ & 0.8285 \\
\hline eGFR, ${ }^{A, B} \mathrm{~mL} / \mathrm{min} / 1.73 \mathrm{~m}^{2}$ & $90.2 \pm 15.3$ & $90.9 \pm 14.9$ & 0.2185 & $91.1 \pm 14.8$ & $90.8 \pm 14.7$ & 0.7277 \\
\hline LVEF,A,B \% & $63.7 \pm 6.5$ & $63.5 \pm 6.5$ & 0.3840 & $63.6 \pm 6.4$ & $63.6 \pm 6.1$ & 0.9297 \\
\hline \multicolumn{7}{|l|}{ Laboratory tests after PCI } \\
\hline Creatinine, $\mu \mathrm{mol} / \mathrm{L}$ & $80.1 \pm 18.7$ & $80.9 \pm 16.6$ & 0.2159 & $80.8 \pm 20.9$ & $82.1 \pm 16.7$ & 0.1744 \\
\hline eGFR, $\mathrm{mL} / \mathrm{min} / 1.73 \mathrm{~m}^{2}$ & $86.0 \pm 15.7$ & $85.6 \pm 15.6$ & 0.5440 & $86.7 \pm 15.2$ & $85.2 \pm 15.6$ & 0.0502 \\
\hline \multicolumn{7}{|l|}{ Medication at discharge, $\mathrm{n}(\%)$} \\
\hline Aspirin ${ }^{A}$ & $2,233(98.8)$ & $1,073(99.4)$ & 0.0990 & $780(99.0)$ & $783(99.4)$ & 0.4034 \\
\hline ClopidogrelA & $2,252(99.7)$ & $1,077(99.8)$ & 0.5164 & 785 (99.6) & 787 (99.9) & 0.3167 \\
\hline Ticagrelor & $7(0.3)$ & $2(0.2)$ & 0.5164 & $3(0.4)$ & $1(0.1)$ & 0.3167 \\
\hline$\beta$-blockers ${ }^{A}$ & $1,989(88.0)$ & $978(90.6)$ & $0.0259^{\star}$ & 705 (89.5) & $706(89.6)$ & 0.9344 \\
\hline ACEIs/ARBs & $1,148(50.8)$ & $560(51.9)$ & 0.7249 & $407(51.6)$ & $407(51.6)$ & 1.0000 \\
\hline Calcium channel blockers & $1,330(58.9)$ & $611(56.6)$ & 0.2179 & $461(58.5)$ & $453(57.5)$ & 0.6831 \\
\hline Nitrates & $2,226(98.5)$ & 1,067 (98.9) & 0.4139 & 775 (98.4) & 779 (98.9) & 0.3904 \\
\hline StatinsA & $2,159(95.6)$ & $1,048(97.1)$ & $0.0306^{*}$ & $754(95.7)$ & 767 (97.3) & 0.0744 \\
\hline
\end{tabular}

Data are expressed as mean \pm standard deviation, number (\%). ACEI, angiotensin-converting-enzyme inhibitor; ARB, angiotensin II receptor blockers; eGFR, estimated glomerular filtration rate; LVEF, left ventricular ejection fraction; MV-PCl, multivessel percutaneous coronary intervention; n, number; NSTEMI, non-ST-segment elevation myocardial infarction; PCl, percutaneous coronary intervention; SV-PCI, single-vessel percutaneous coronary intervention. ${ }^{A}$ Risk-adjusting variables selected for the multivariable Cox models. ${ }^{B}$ Risk-adjusting variables selected for the propensity score analysis. ${ }^{*} \mathrm{P}$ values indicating statistical significance.

culprit lesion was identified according to the patient's electrocardiogram, non-invasive imaging manifestations, and coronary angiography records. For non-culprit lesions with percentage stenosis between $50 \%$ and $70 \%$, a variety of factors will be taken into consideration to decide whether to treat such a lesion, including procedural aspects (i.e., intracoronary imaging to confirm lesion characteristics and stenotic severity, such as intravascular ultrasound (IVUS), optical coherence tomography (OCT); physiological assessment to investigate if the lesion leads to ischemia: fractional flow reserve (FFR)) and peri-procedural aspects (i.e., evaluation of patient baseline condition, assessment of bleeding risk if prolonged dual antiplatelet therapy is required, socioeconomic status).

\section{Follow up}

Follow-up data were collected by an independent group of clinical research coordinators via telephone interviews or by outpatient visits at 1, 6, and 12 months and then once every year. All patients were advised to return for coronary angiography if indicated by symptoms or clinical evidence of myocardial ischemia.

\section{Endpoints}

The primary endpoint was major adverse cardiovascular and cerebrovascular events (MACCE) (the composite of all-cause death, cardiac death, MI, unplanned revascularization, or stroke) at the 2-year follow up. The secondary endpoints were the individual components of MACCE, in-stent thrombosis and bleeding. Bleeding was quantified according to Bleeding Academic Research Consortium Definition (BARC) criteria, including type 2, 3 and 5 in the analysis. ${ }^{19}$ Other outcomes included in-hospital mortality and contrast-induced acute kidney injury (CI-AKI). CIAKI was defined as a rise in serum creatinine by $\geq 0.3 \mathrm{mg} / \mathrm{dL}$ $(26.5 \mathrm{mmol} / \mathrm{L})$ or $\mathrm{a} \geq 50 \%$ elevation from baseline after PCI 
Table 2. Angiographic and Procedural Characteristics Stratified by PCI Strategy

\begin{tabular}{|c|c|c|c|c|c|c|}
\hline \multirow[b]{2}{*}{ Characteristics } & \multicolumn{3}{|c|}{ All patients $(n=3,338)$} & \multicolumn{3}{|c|}{ Matched patients $(n=1,576)$} \\
\hline & $\begin{array}{c}\text { SV-PCl } \\
(n=2,259)\end{array}$ & $\begin{array}{c}\text { MV-PCI } \\
(n=1,079)\end{array}$ & $P$ value & $\begin{array}{l}\text { SV-PCI } \\
(n=788)\end{array}$ & $\begin{array}{l}\text { MV-PCl } \\
(n=788)\end{array}$ & $P$ value \\
\hline \multicolumn{7}{|l|}{ SYNTAX score } \\
\hline Pre-procedure ${ }^{\mathrm{B}}$ & $11.2 \pm 7.7$ & $15.2 \pm 7.8$ & $<0.0001^{*}$ & $13.2 \pm 7.8$ & $13.6 \pm 6.9$ & 0.3854 \\
\hline 0-22, n (\%) & $2,036(90.7)$ & $896(83.2)$ & $<0.0001^{*}$ & $688(87.3)$ & $706(89.6)$ & 0.3431 \\
\hline 23-32, n (\%) & $181(8.1)$ & $154(14.3)$ & & $86(10.9)$ & $72(9.1)$ & \\
\hline$\geq 33, \mathrm{n}(\%)$ & $27(1.2)$ & $27(2.5)$ & & $14(1.8)$ & $10(1.3)$ & \\
\hline Post-procedure ${ }^{B}$ & $4.1 \pm 5.7$ & $3.2 \pm 4.6$ & $<0.0001^{*}$ & $3.3 \pm 4.7$ & $3.5 \pm 5.0$ & 0.4543 \\
\hline $0-22, \mathrm{n}(\%)$ & $2,203(98.8)$ & $1,069(99.3)$ & 0.3482 & $784(99.5)$ & $780(99.0)$ & 0.2464 \\
\hline 23-32, n (\%) & $23(1.0)$ & $8(0.7)$ & & $4(0.5)$ & $8(1.0)$ & \\
\hline$\geq 33, \mathrm{n}(\%)$ & $3(0.1)$ & 0 & & 0 & 0 & \\
\hline Left main involvement, ${ }^{A, B} \mathbf{n}(\%)$ & $159(7.0)$ & $102(9.5)$ & $0.0151^{*}$ & $67(8.5)$ & $64(8.1)$ & 0.7843 \\
\hline \multicolumn{7}{|l|}{ Lesion location, $n(\%)$} \\
\hline LAD+LCX'A & 445 (19.7) & $179(16.6)$ & $0.0311^{*}$ & $152(19.3)$ & $145(18.4)$ & 0.6521 \\
\hline $\mathrm{LAD}+\mathrm{RCA}^{\mathrm{A}}$ & $531(23.5)$ & $125(11.6)$ & $<0.0001^{*}$ & $128(16.2)$ & $96(12.2)$ & $0.0210^{*}$ \\
\hline $\mathrm{LCX}+\mathrm{RCA} A$ & $219(9.7)$ & $89(8.2)$ & 0.1769 & $40(5.1)$ & $79(10.0)$ & $0.0002^{*}$ \\
\hline Tri-vessel disease ${ }^{B}$ & $1,064(47.1)$ & $686(63.6)$ & $<0.0001^{*}$ & $468(59.4)$ & $468(59.4)$ & 1.0000 \\
\hline \multicolumn{7}{|l|}{ Anatomical characteristics, $\mathrm{n}(\%)$} \\
\hline Chronic total occlusion ${ }^{B}$ & $143(6.3)$ & $124(11.5)$ & $<0.0001^{*}$ & $72(9.1)$ & $76(9.6)$ & 0.7298 \\
\hline Heavy calcification ${ }^{A, B}$ & $60(2.7)$ & $54(5.0)$ & $0.0005^{\star}$ & $33(4.2)$ & $35(4.4)$ & 0.8042 \\
\hline Bifurcation lesion ${ }^{A, B}$ & $358(15.8)$ & $302(28.0)$ & $<0.0001^{*}$ & $186(23.6)$ & $180(22.8)$ & 0.7204 \\
\hline Ostial lesion ${ }^{A, B}$ & $337(14.9)$ & $257(23.8)$ & $<0.0001^{*}$ & $164(20.8)$ & $163(20.7)$ & 0.9505 \\
\hline \multicolumn{7}{|l|}{ Puncture site, $n(\%)$} \\
\hline Radial artery & $2,082(92.2)$ & $1,015(94.1)$ & $0.0468^{*}$ & $726(92.1)$ & $747(94.8)$ & 0.0323 \\
\hline Femoral artery & $137(6.1)$ & $50(4.6)$ & 0.0927 & $53(6.7)$ & $31(3.9)$ & 0.0136 \\
\hline Other approaches & $38(1.7)$ & $14(1.3)$ & $0.4013^{*}$ & $9(1.1)$ & $10(1.3)$ & 0.8175 \\
\hline IVUS use, ${ }^{\mathrm{A}, \mathrm{B}}$ n (\%) & $85(3.8)$ & $101(9.4)$ & $<0.0001^{*}$ & $49(6.2)$ & $59(7.5)$ & 0.3188 \\
\hline Number of stents & $1.5 \pm 0.8$ & $2.9 \pm 1.2$ & $<0.0001^{*}$ & $1.7 \pm 0.9$ & $2.7 \pm 1.1$ & $<0.0001$ \\
\hline \multicolumn{7}{|l|}{ Stent type } \\
\hline BMS, n (\%) & $16(0.7)$ & $1(0.1)$ & $0.0194^{*}$ & $7(0.9)$ & $1(0.1)$ & 0.0334 \\
\hline DES, ${ }^{B}$ n (\%) & $1,876(83.0)$ & $655(60.7)$ & $<0.0001^{*}$ & $559(70.9)$ & $558(70.8)$ & 0.9558 \\
\hline
\end{tabular}

Data are expressed as mean \pm standard deviation, number (\%). BMS, bare metal stent; DES, drug-eluting stent; IVUS, intravascular ultrasound; LAD, left anterior descending coronary artery; LCX, left circumflex coronary artery; RCA, right coronary artery; SYNTAX, synergy between percutaneous coronary intervention with taxus and cardiac surgery. Other abbreviations as in Table 1. ${ }^{\text {ARisk-adjusting variables }}$ selected for the multivariable Cox models. ${ }^{B}$ Risk-adjusting variables selected for the propensity score analysis. ${ }^{*} \mathrm{P}$ values indicating statistical significance.

Table 3. In Hospital and 2-Year Clinical Outcomes in the 2 Study Groups

\begin{tabular}{|c|c|c|c|c|c|c|}
\hline & \multicolumn{3}{|c|}{ All patients $(n=3,338)$} & \multicolumn{3}{|c|}{ Matched patients $(n=1,576)$} \\
\hline & $\begin{array}{c}\text { SV-PCI } \\
(n=2,259)\end{array}$ & $\begin{array}{c}\text { MV-PCI } \\
(n=1,079)\end{array}$ & $P$ value & $\begin{array}{l}\text { SV-PCI } \\
(n=788)\end{array}$ & $\begin{array}{l}\text { MV-PCl } \\
(n=788)\end{array}$ & $P$ value \\
\hline \multicolumn{7}{|l|}{ In-hospital outcomes, n (\%) } \\
\hline In-hospital mortality & $1(0.0)$ & $1(0.1)$ & 0.5926 & $-^{\mathrm{B}}$ & - & - \\
\hline Contrast-induced acute kidney injury & $186(8.2)$ & $99(9.2)$ & 0.4903 & $69(8.8)$ & $71(9.0)$ & 0.9400 \\
\hline \multicolumn{7}{|l|}{ 2-year clinical outcomes, n (\%) } \\
\hline MACCE & $296(13.1)$ & $151(14.0)$ & 0.7349 & $119(15.1)$ & $117(14.8)$ & 0.8364 \\
\hline All-cause death & $25(1.1)$ & $11(1.0)$ & 0.8019 & $10(1.3)$ & $11(1.4)$ & 0.8561 \\
\hline Cardiac death & $13(0.6)$ & $6(0.6)$ & 0.8003 & $4(0.5)$ & $5(0.6)$ & 0.7622 \\
\hline Myocardial infarction & $40(1.8)$ & $18(1.7)$ & 0.9280 & $14(1.8)$ & $12(1.5)$ & 0.8336 \\
\hline Unplanned revascularization & $215(9.5)$ & $109(10.1)$ & 0.9535 & $91(11.5)$ & $83(10.5)$ & 0.4284 \\
\hline Stroke & $35(1.5)$ & $24(2.2)$ & 0.1653 & $11(1.4)$ & $20(2.5)$ & 0.0918 \\
\hline In-stent thrombosis & $19(0.8)$ & $9(0.8)$ & 0.7098 & $9(1.1)$ & $7(0.9)$ & 0.6527 \\
\hline Bleeding $^{A}$ & $153(6.8)$ & $64(5.9)$ & 0.5200 & $52(6.6)$ & $51(6.5)$ & 0.8433 \\
\hline
\end{tabular}

MACCE, major adverse cardiac and cerebrovascular events. Other abbreviations as in Table 1. ABleeding was quantified according to Bleeding Academic Research Consortium Definition (BARC) criteria, including types 2, 3 and 5 in the analysis. BNo event happened in matched patients. 
A)

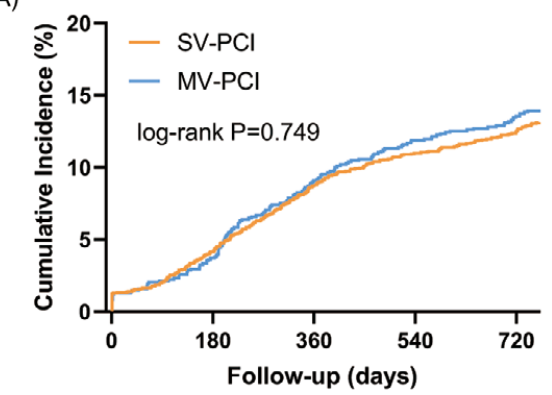

Number at risk

$\begin{array}{llllll}\text { SV-PCl } & 2259 & 2165 & 2061 & 2011 & 1976\end{array}$

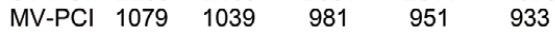

C)

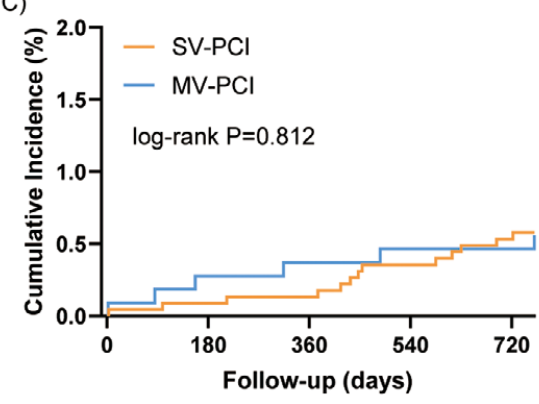

Number at risk

$\begin{array}{llllll}\text { SV-PCl } & 2259 & 2257 & 2256 & 2251 & 2247\end{array}$

$\begin{array}{llllll}\text { MV-PCI } & 1079 & 1076 & 1075 & 1074 & 1074\end{array}$

E)

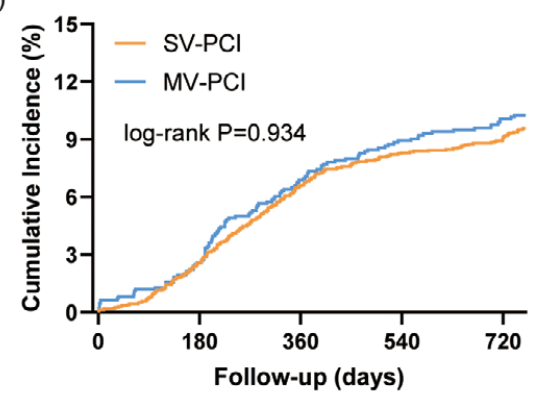

Number at risk

$\begin{array}{llllll}\text { SV-PCI } & 2259 & 2201 & 2110 & 2078 & 2054\end{array}$

$\begin{array}{llllll}\mathrm{MV}-\mathrm{PCl} & 1079 & 1051 & 1005 & 983 & 971\end{array}$

G)

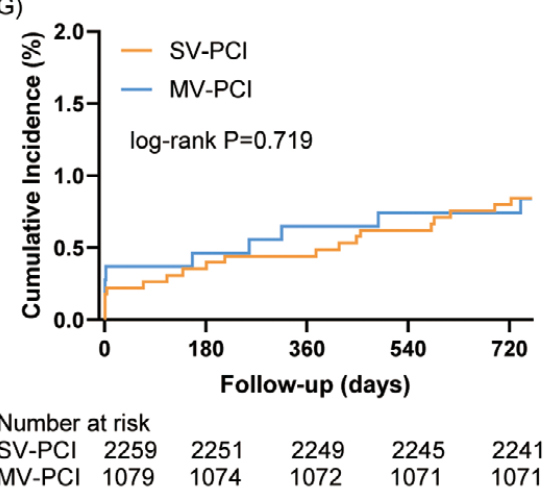

B)

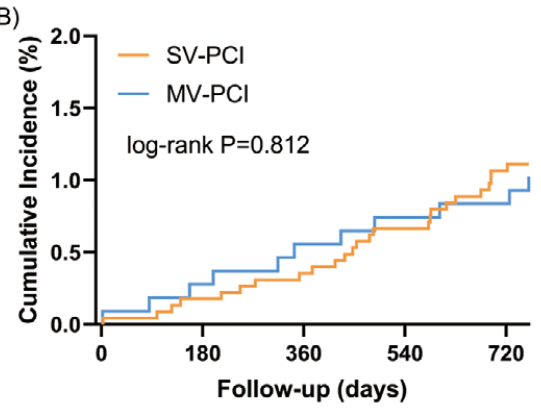

Number at risk

SV-PCI $2259 \quad 2255 \quad 2251 \quad 2244 \quad 2235$

$\begin{array}{llllll}\text { MV-PCI } & 1079 & 1076 & 1073 & 1071 & 1070\end{array}$

D)

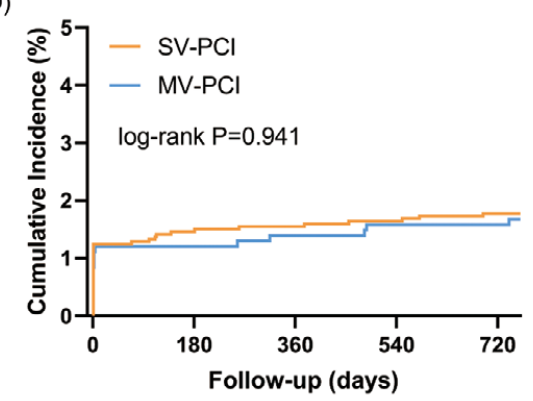

Number at risk

$\begin{array}{llllll}\text { SV-PCI } & 2259 & 2226 & 2224 & 2222 & 2219\end{array}$ $\begin{array}{llllll}\mathrm{MV}-\mathrm{PCl} & 1079 & 1066 & 1064 & 1062 & 1062\end{array}$

F)

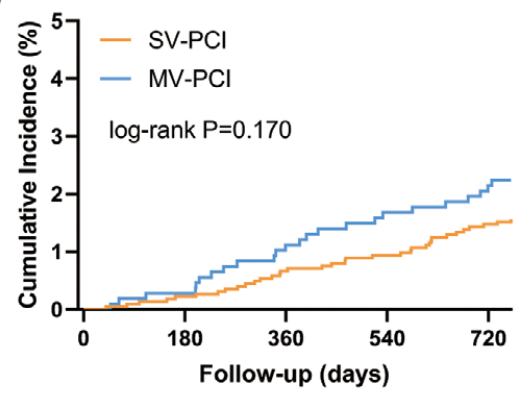

Number at risk

$\begin{array}{llllll}\text { SV-PCl } & 2259 & 2254 & 2244 & 2238 & 2226\end{array}$ $\begin{array}{llllll}\mathrm{MV}-\mathrm{PCl} & 1079 & 1076 & 1067 & 1061 & 1056\end{array}$

H)

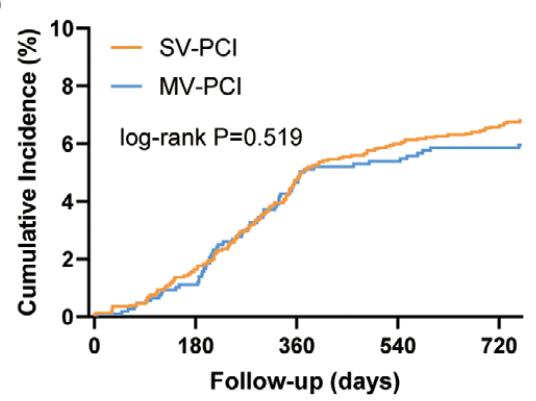

Number at risk

SV-PCI $2259 \quad 2222 \quad 2152 \quad 2124 \quad 2111$ $\begin{array}{llllll}\mathrm{MV}-\mathrm{PCl} & 1079 & 1067 & 1029 & 1021 & 1016\end{array}$

Figure 2. Cumulative incidence curves for the primary and secondary endpoints for patients undergoing SV-PCl and MV-PCl. (A-H) Cumulative incidence curves for (A) MACCE, (B) all-cause death, (C) cardiac death, (D) myocardial infarction, (E) unplanned revascularization, $(\mathbf{F})$ stroke, $(\mathbf{G})$ in-stent thrombosis, $(\mathbf{H})$ bleeding. SV-PCl, single-vessel percutaneous coronary intervention; $\mathrm{MV}-\mathrm{PCl}$, multivessel percutaneous coronary intervention; MACCE, major adverse cardiac and cerebrovascular events. 


\begin{tabular}{|c|c|c|c|c|}
\hline & $\begin{array}{l}\text { Unadjusted HR } \\
\quad(95 \% \mathrm{Cl})\end{array}$ & $P$ value & $\begin{array}{l}\text { Adjusted HR } \\
(95 \% \mathrm{Cl})\end{array}$ & $P$ value \\
\hline \multicolumn{5}{|l|}{ All patients $(n=3,338)$} \\
\hline MACCE & $1.031(0.854-1.246)$ & 0.7482 & $0.967(0.792-1.180)$ & 0.7396 \\
\hline All-cause death & $0.925(0.481-1.779)$ & 0.8128 & $1.085(0.537-2.192)$ & 0.8194 \\
\hline Cardiac death & $1.110(0.471-2.618)$ & 0.8119 & $1.266(0.515-3.117)$ & 0.6071 \\
\hline Myocardial infarction & $0.981(0.588-1.636)$ & 0.9412 & $1.023(0.596-1.755)$ & 0.9352 \\
\hline Unplanned revascularization & $1.010(0.806-1.265)$ & 0.9334 & $0.924(0.731-1.167)$ & 0.5070 \\
\hline Stroke & $1.396(0.865-2.252)$ & 0.1717 & $1.411(0.854-2.332)$ & 0.1792 \\
\hline In-stent thrombosis & $1.138(0.563-2.299)$ & 0.7190 & $0.966(0.462-2.019)$ & 0.9267 \\
\hline Bleeding & $0.911(0.687-1.209)$ & 0.5196 & $0.931(0.693-1.251)$ & 0.6366 \\
\hline \multicolumn{5}{|l|}{ Matched patients $(n=1,576)$} \\
\hline MACCE & $0.965(0.753-1.236)$ & 0.7772 & $1.000(0.770-1.299)$ & 1.0000 \\
\hline All-cause death & $1.082(0.477-2.452)$ & 0.8507 & $1.000(0.434-2.307)$ & 1.0000 \\
\hline Cardiac death & $1.184(0.361-3.880)$ & 0.7802 & $1.000(0.290-3.454)$ & 1.0000 \\
\hline Myocardial infarction & $0.929(0.459-1.878)$ & 0.8367 & $0.750(0.355-1.585)$ & 0.4513 \\
\hline Unplanned revascularization & $0.884(0.659-1.184)$ & 0.4076 & $0.917(0.673-1.249)$ & 0.5815 \\
\hline Stroke & $1.772(0.897-3.497)$ & 0.0994 & $1.909(0.920-3.959)$ & 0.0824 \\
\hline In-stent thrombosis & $0.810(0.336-1.955)$ & 0.6395 & $0.636(0.247-1.642)$ & 0.3499 \\
\hline Bleeding & $0.963(0.662-1.399)$ & 0.8416 & $0.906(0.613-1.338)$ & 0.6193 \\
\hline \multicolumn{5}{|l|}{ Weighted } \\
\hline MACCE & - & - & $0.979(0.808-1.185)$ & 0.8258 \\
\hline All-cause death & - & - & $1.235(0.641-2.380)$ & 0.5274 \\
\hline Cardiac death & - & - & $1.331(0.566-3.128)$ & 0.5118 \\
\hline Myocardial infarction & - & - & $0.974(0.565-1.679)$ & 0.9240 \\
\hline Unplanned revascularization & - & - & $0.925(0.738-1.160)$ & 0.5011 \\
\hline Stroke & - & - & $1.347(0.815-2.227)$ & 0.2455 \\
\hline In-stent thrombosis & - & - & $1.131(0.544-2.353)$ & 0.7412 \\
\hline Bleeding $^{A}$ & - & - & $0.906(0.672-1.221)$ & 0.5163 \\
\hline
\end{tabular}

$\mathrm{Cl}$, confidence interval; HR, hazard ratio. Other abbreviations as in Tables 1,3. ${ }^{A}$ Bleeding was quantified according to BARC criteria, including types 2, 3 and 5 in the analysis.

during hospital stay. ${ }^{20}$ Endpoint events were adjudicated by 2 independent cardiologists, and disagreement was resolved by consensus.

\section{Statistical Analysis}

Categorical variables are shown as numbers and percentages. Continuous variables are expressed as mean \pm standard deviations. Statistical differences were assessed by using the Student's t-test or the Mann-Whitney U-test for continuous variables, and by Pearson's chi-square test or Fisher's exact test for categorical variables. Cumulative incidences of clinical events were calculated using the Kaplan-Meier method, and comparisons were made with the log-rank test. Cox proportional hazards regression analyses were performed to estimate the hazard ratios (HRs) for PCI strategy comparisons and their 95\% confidence intervals (CIs). We justified for age, sex, and 21 clinically relevant risk-adjusting variables that changed the unadjusted HR by at least 10 percent when added to multivariable Cox regression models. Proportional hazards assumption was evaluated by testing the significance of an interaction term of the PCI strategy and follow-up time, and by computing cumulative incidence plots. The timedependent Cox regression model was applicated when the proportional hazards assumption was violated. Subgroup analyses were performed using a few preselected risk factors of interest (age, gender, presence of diabetes, left ventricular ejection fraction, pre-procedure synergy between PCI with taxus and cardiac surgery (SYNTAX) score, and presence of left main disease) to analyze interactions between PCI strategy and the selected factors for the outcomes.

Propensity-score matching (PSM) and inverse probability of treatment weighting (IPTW) were undertaken as sensitivity analyses. The propensity score was generated by logistic regression analysis with 22 baseline variables related to PCI strategy and/or the outcome variables (Table $\mathbf{1}$ and Table 2). The patients in the 2 groups were matched in a 1:1 manner using a greedy matching strategy algorithm, with a caliper width equal to 0.02 of the standard deviation of the logit of the propensity score. The propensity score and (1-propensity score) were used to calculated the inverseprobability-weighting weights of SV-PCI and MV-PCI.

Two-tailed $\mathrm{P}$ values of $<0.05$ were considered to be statistically significant. PSM was conducted with the R statistical software version 3.4.0 (www.r-project.org). The other analyses were conducted with SPSS version 22.0 (IBM, Armonk, NY, USA).

\section{Results}

\section{Patient Characteristics}

Among the 3,338 patients included in the study, 2,259 $(67.7 \%)$ underwent SV-PCI whereas 1,079 (22.3\%) underwent MV-PCI. Two-year follow up was available for all 


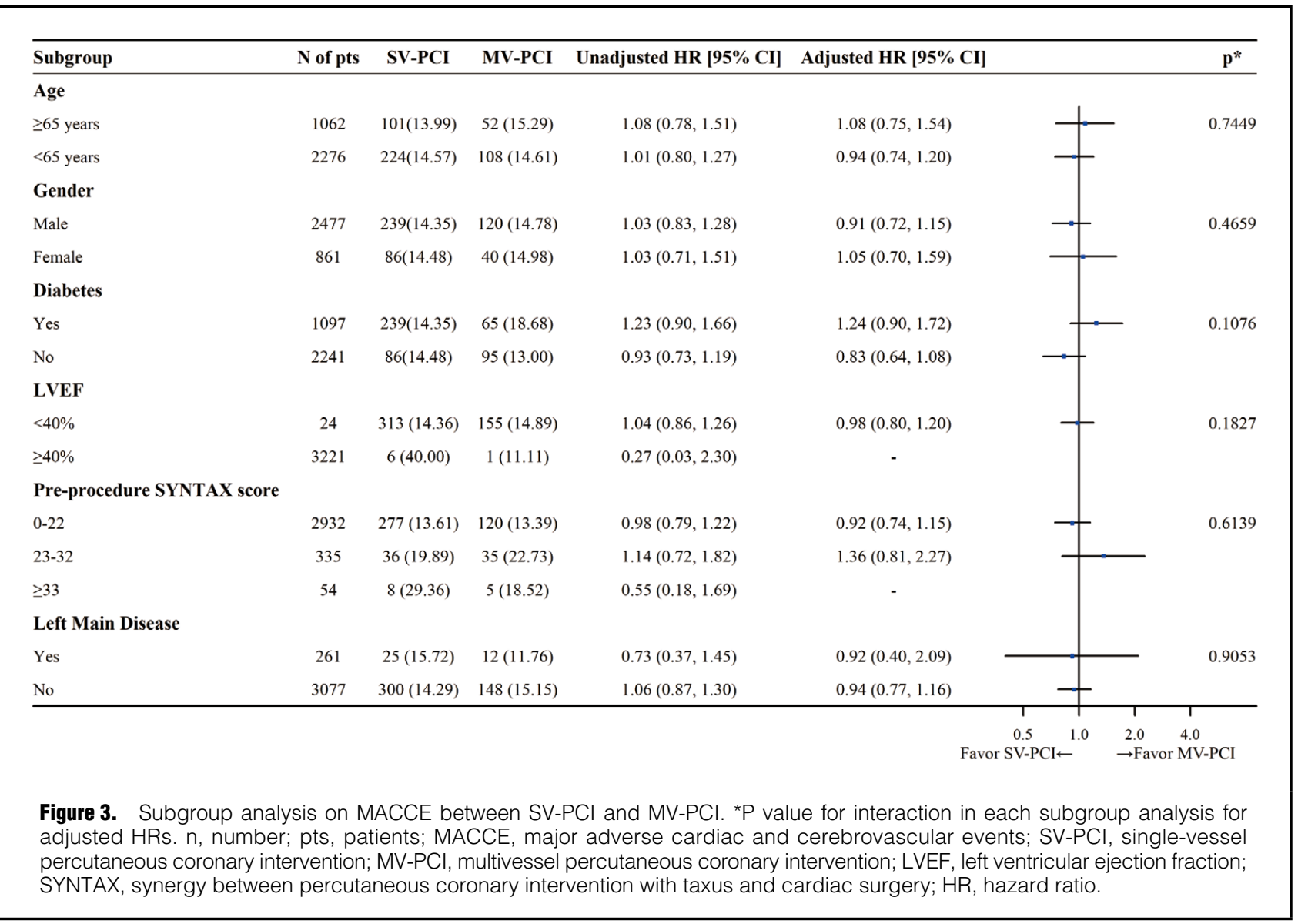

patients with a median follow-up duration of 2.1 (IQR: 2.1-2.1 and range: $0-2.1$ ) years. The baseline characteristics were mostly comparable between the 2 groups before PSM, except that MV-PCI patients were more likely to present with non-ST-segment elevation myocardial infarction, had higher body mass index, a lower rate of prior PCI, with $\beta$-blockers and statins more frequently prescribed at discharge $(\mathrm{P}<0.05)$ (Table 1). Angiographic and procedural characteristics were significantly different between the 2 groups in several aspects before PSM. Patients in the MV-PCI group had higher pre-procedure SYNTAX scores and lower post-procedure SYNTAX scores (Table 2). Patients with MV-PCI were more likely to have complex anatomical characteristics, reflected by higher rates of tri-vessel disease, chronic total occlusion, bifurcation lesion, and ostial lesion compared with the SV-PCI group (Table 2). Higher rates of IVUS use were seen in the MV-PCI group (Table 2). Patients who underwent MV-PCI had more stents implanted; however, the percentage of drug-eluting stent (DES) implantation was significantly lower (Table 2).

\section{Clinical Outcomes}

In terms of in-hospital clinical outcomes, no significant difference was observed for the incidence of CI-AKI and mortality (all $\mathrm{P}>0.05$ ) (Table 3).

The analysis of 2-year MACCE showed no significant difference between the 2 groups (SV-PCI: $n=296$ [13.1\%] vs. MV-PCI: $\mathrm{n}=151$ [14.0\%], $\mathrm{P}=0.735$; unadjusted $\mathrm{HR}=1.031$;
95\% CI: $0.854-1.246)$, and the risk of the primary outcome measure remained neutral after adjustment (adjusted $\mathrm{HR}=0.967$; 95\% CI: 0.792-1.180) (Figure 2, Table 3 and Table 4). The cumulative incidences and the risks of the secondary outcome measures at 2 years were not significantly different between the 2 groups before and after adjustment (Figure 2, Table 3 and Table 4).

\section{Subgroup Analysis}

For subgroup analyses including age, gender, presence of diabetes, left ventricular ejection fraction, pre-procedure SYNTAX score, and presence of left main disease, there was no significant interaction between each subgroup factor and the effect of PCI strategy in terms of MACCE (all P for interaction $>0.05$ ) (Figure 3).

\section{Sensitivity Analysis}

The PSM analysis showed consistent results with the analysis based on all patients; that is, that there were no significant differences in the primary and secondary outcome measures between the SV-PCI group and the MV-PCI group. Overall, 788 MV-PCI patients were propensity matched with SV-PCI patients at a 1:1 ratio. After PSM, most characteristics became more comparable between the 2 groups (Table 1 and Table 2). Risk of 2-year primary and secondary endpoints were similar between the groups before and after adjustment ( $\mathrm{P}>0.05)$ (Supplementary Figure, Table 3). IPTW analysis revealed similar results (Table 3). 


\section{Discussion}

This is a large retrospective cohort study. The main finding of our study is that the cumulative incidences and adjusted risks of 2-year MACCE and secondary outcome measures showed no significant difference between patients treated with MV-PCI vs. SV-PCI.

Our finding is consistent with the results of some previous studies. ${ }^{8,11-13}$ Admittedly, MV-PCI at one time can achieve more complete revascularization, avoid additional risks and reduce costs from otherwise multistage procedures for NSTE-ACS patients with MV-CAD. Nevertheless, one-stage MV-PCI has been reported to be associated with an elevated risk of complications, including stent thrombosis (possibly due to hypercoagulative status associated with acute coronary syndrome and increased number or length of stents), inflammatory burden (mainly due to increased damage to coronary artery epithelium and increased vascular exposure to stent polymers) and contrast-induced nephropathy (due to increased amount of contrast use). ${ }^{\mathbf{1 0}}$ However, we did not observe an increased risk of CI-AKI in our study. Furthermore, treating non-infarction related artery and implanting more stents may cause additional myocardial injury related to the procedure. ${ }^{21} \mathrm{Owing}$ to the lack of powerful evidence favoring MV-PCI in terms of hard clinical endpoints, the optimal PCI strategy for multivessel lesions in the setting of NSTE-ACS remains controversial.

Contrary to our findings, some studies found that MVPCI was associated with lower mortality, 5,6,17,18 and some reported that MV-PCI reduced unplanned repeat revascularization. 4,14-16 The possible explanations are listed as follows. First, the low-risk population of the study led to relatively low event rates at follow up in both groups, resulting in no significant difference in 2-year MACCE between the 2 groups. Second, operators were more likely to perform MV-PCI in higher-risk patients, which may offset its benefits. Third, although patients in the MV-PCI group had more lesions treated than those in the SV-PCI group, not all of them received complete revascularization, thus, the difference in prognosis between groups was not significant.

Moreover, the proportion of DES among all the implanted stents exceeded $99 \%$, which is much higher than in other similar studies. A DES reduces restenosis by approximately $50-70 \%$ in comparison with BMS, and the new-generation DES performs even better, especially in reducing late and very late stent thrombosis, ${ }^{\mathbf{2 2}, 23}$ leading to a lower rate of unplanned revascularization. In addition, thanks to the expertise of our interventionalists and the application of IVUS to guide the treatment of complex lesions, accurate pinpointing of the culprit vessel was achieved. Evidence from several meta-analyses suggested better outcomes with IVUS-guided PCI in terms of reduced restenosis and repeat revascularization, regardless of stent type. ${ }^{24-27}$ This enabled patients who underwent culprit-only SV-PCI to have a better chance of getting the correct unstable lesion solved at the initial procedure. Therefore, lesions scheduled to be intervened in future planned procedures are more frequently stable plaques, resulting in reduced unplanned repeat revascularization for the SV-PCI group.

To the best of our knowledge, most studies in this field started before $2005,{ }^{6-8,11,13-17}$ and some had enrolled patients for 10 years, ${ }^{\mathbf{5}, 6,15,16}$ which may limit their generalizability.
Contemporary practice has changed significantly in the past decades, with an increase in the use of a radial approach, DESs, and IVUS, leading to better clinical outcomes with PCI. Compared to these studies, our research provides more valuable evidence for current clinical practice.

Potential limitations of our study warrant discussion. First, this is an observational study. Although we used extensive adjustments and PSM to minimize potential confounders, there remain unmeasured residual confounders. Second, our study was conducted in a specialized cardiovascular hospital, and most of the patients were younger, had less severe comorbidities and were in a better clinical status than those in previous similar studies, thus, the incidence of MACCE was relatively low. This could limit the generalizability of our findings. Third, our data were not able to provide information on whether patients in the MV-PCI group received complete revascularization. Fourth, although intravascular imaging and physiological assessment have been used in patients as per standard protocol, these data are not available in our database. Finally, we are unable to adjust for the confounding effect of lesion location and severity of non-culprit lesions, as we cannot pinpoint the culprit lesion location for MV-PCI patients based on the available data.

\section{Conclusions}

In NSTE-ACS patients with MV-CAD, multivessel PCI in the index procedure is not superior to SV-PCI on the culprit vessel. Future randomized controlled trials are needed to validate the effect of multivessel PCI, especially functionguided complete revascularization, in the setting of current standard clinical practice.

\section{Acknowledgments}

The authors wish to thank all staff members from Fuwai Hospital for their help in recruiting patients, follow up and monitoring as part of this study.

\section{Sources of Funding}

The study was funded by the National Key Research and Development Program of China (No. 2016YFC1301301) and the National Natural Science Foundation of China (No. 81770365).

\section{Disclosures}

The authors declare that there are no conflicts of interest.

\section{IRB Information}

Institutional Review Board of Fuwai Hospital (No. 2013-449) approved this study.

\section{Data Availability}

The deidentified participant data will not be shared.

\section{References}

1. Amsterdam EA, Wenger NK, Brindis RG, Casey DJ, Ganiats TG, Holmes DJ, et al. 2014 AHA/ACC Guideline for the Management of Patients with Non-ST-Elevation Acute Coronary Syndromes: A report of the American College of Cardiology/ American Heart Association Task Force on Practice Guidelines. J Am Coll Cardiol 2014; 64: e139-e228.

2. Roffi M, Patrono C, Collet J, Mueller C, Valgimigli M, Andreotti F, et al. 2015 ESC Guidelines for the management of acute coronary syndromes in patients presenting without persistent ST-segment elevation. Eur Heart J 2016; 37: 267-315.

3. Neumann F, Sousa-Uva M, Ahlsson A, Alfonso F, Banning AP, Benedetto U, et al. 2018 ESC/EACTS Guidelines on myocardial 
revascularization. Eur Heart J 2019; 40: 87-165.

4. Correia C, Galvao BC, Martins J, Arantes C, Abreu G, Quina $\mathrm{C}$, et al. Multivessel vs. culprit-only revascularization in patients with non-ST-elevation acute coronary syndromes and multivessel coronary disease. Rev Port Cardiol 2018; 37: 143-154.

5. Rathod KS, Koganti S, Jain AK, Astroulakis Z, Lim P, Rakhit $\mathrm{R}$, et al. Complete versus culprit-only lesion intervention in patients with acute coronary syndromes. J Am Coll Cardiol 2018; 72: $1989-1999$.

6. Quadri G, D'Ascenzo F, Moretti C, D'Amico M, RaposeirasRoubin S, Abu-Assi E, et al. Complete or incomplete coronary revascularisation in patients with myocardial infarction and multivessel disease: A propensity score analysis from the "reallife" BleeMACS (Bleeding complications in a Multicenter registry of patients discharged with diagnosis of Acute Coronary Syndrome) registry. EuroIntervention 2017; 13: 407-414.

7. Brener SJ, Milford-Beland S, Roe MT, Bhatt DL, Weintraub WS, Brindis RG. Culprit-only or multivessel revascularization in patients with acute coronary syndromes. Am Heart J 2008; 155: $140-146$.

8. Mariani G, De Servi S, Dellavalle A, Repetto S, Chierchia S, D'Urbano M, et al. Complete or incomplete percutaneous coronary revascularization in patients with unstable angina in stent era: Are early and one-year results different? Catheter Cardiovasc Interv 2001; 54: 448-453.

9. Farooq V, Serruys PW, Garcia-Garcia HM, Zhang Y, Bourantas $\mathrm{CV}$, Holmes DR, et al. The negative impact of incomplete angiographic revascularization on clinical outcomes and its association with total occlusions: The SYNTAX (Synergy Between Percutaneous Coronary Intervention with Taxus and Cardiac Surgery) trial. J Am Coll Cardiol 2013; 61: 282-294.

10. Li Z, Zhou Y, Xu Q, Chen X. Staged versus one-time complete revascularization with percutaneous coronary intervention in STEMI patients with multivessel disease: A systematic review and meta-analysis. PLoS One 2017; 12: e0169406.

11. Wang TY, McCoy LA, Bhatt DL, Rao SV, Roe MT, Resnic FS, et al. Multivessel vs culprit-only percutaneous coronary intervention among patients 65 years or older with acute myocardial infarction. Am Heart J 2016; 172: 9-18.

12. Hassanin A, Brener SJ, Lansky AJ, Xu K, Stone GW. Prognostic impact of multivessel versus culprit vessel only percutaneous intervention for patients with multivessel coronary artery disease presenting with acute coronary syndrome. EuroIntervention 2015; 11: $293-300$.

13. Brener SJ, Murphy SA, Gibson CM, DiBattiste PM, Demopoulos LA, Cannon CP. Efficacy and safety of multivessel percutaneous revascularization and tirofiban therapy in patients with acute coronary syndromes. Am J Cardiol 2002; 90: 631-633.

14. Lee HJ, Song YB, Hahn J, Kim SM, Yang JH, Choi JH, et al. Multivessel vs single-vessel revascularization in patients with nonST-segment elevation acute coronary syndrome and multivessel disease in the drug-eluting stent era. Clin Cardiol 2011; 34: $160-165$.

15. Zapata GO, Lasave LI, Kozak F, Damonte A, Meiriño A, Rossi $\mathrm{M}$, et al. Culprit-only or multivessel percutaneous coronary stenting in patients with non-ST-segment elevation acute coronary syndromes: One-year follow-up. J Interv Cardiol 2009; 22: $329-335$
16. Shishehbor MH, Lauer MS, Singh IM, Chew DP, Karha J, Brener SJ, et al. In unstable angina or non-ST-segment acute coronary syndrome, should patients with multivessel coronary artery disease undergo multivessel or culprit-only stenting? $J$ Am Coll Cardiol 2007; 49: 849-854.

17. Onuma Y, Muramatsu T, Girasis C, Kukreja N, Garcia-Garcia HM, Daemen J, et al. Single-vessel or multivessel PCI in patients with multivessel disease presenting with non-ST-elevation acute coronary syndromes. EuroIntervention 2013; 9: 916-922.

18. Kim MC, Jeong MH, Ahn Y, Kim JH, Chae SC, Kim YJ, et al. What is optimal revascularization strategy in patients with multivessel coronary artery disease in non-ST-elevation myocardial infarction? Multivessel or culprit-only revascularization. Int J Cardiol 2011; 153: 148-153.

19. Mehran R, Rao SV, Bhatt DL, Gibson CM, Caixeta A, Eikelboom $\mathrm{J}$, et al. Standardized bleeding definitions for cardiovascular clinical trials. Circulation 2011; 123: 2736-2747.

20. Khwaja A. KDIGO clinical practice guidelines for acute kidney injury. Nephron Clin Pract 2012; 120: c179-c184.

21. Bhatt DL, Topol EJ. Periprocedural cardiac enzyme elevation predicts adverse outcomes. Circulation 2005; 112: 906-922.

22. Tada T, Byrne RA, Simunovic I, King LA, Cassese S, Joner M, et al. Risk of stent thrombosis among bare-metal stents, firstgeneration drug-eluting stents, and second-generation drug-eluting stents: Results from a registry of 18,334 patients. JACC Cardiovasc Interv 2013; 6: $1267-1274$

23. Raber L, Magro M, Stefanini GG, Kalesan B, van Domburg RT, Onuma Y, et al. Very late coronary stent thrombosis of a newer-generation everolimus-eluting stent compared with early-generation drug-eluting stents: A prospective cohort study. Circulation 2012; 125: 1110-1121.

24. Buccheri S, Franchina G, Romano S, Puglisi S, Venuti G, D'Arrigo P, et al. Clinical outcomes following intravascular imaging-guided versus coronary angiography - guided percutaneous coronary intervention with stent implantation: A systematic review and Bayesian network meta-analysis of 31 studies and 17,882 patients. JACC Cardiovasc Interv 2017; 10: 2488-2498.

25. Nerlekar N, Cheshire CJ, Verma KP, Ihdayhid AR, McCormick LM, Cameron JD, et al. Intravascular ultrasound guidance improves clinical outcomes during implantation of both firstand second-generation drug-eluting stents: A meta-analysis. EuroIntervention 2017; 12: 1632-1642.

26. Lodi-Junqueira L, de Sousa MR, Da PL, Kelles SM, Amaral $\mathrm{CF}$, Ribeiro AL. Does intravascular ultrasound provide clinical benefits for percutaneous coronary intervention with bare-metal stent implantation? A meta-analysis of randomized controlled trials. Syst Rev 2012; 1: 42.

27. Parise H, Maehara A, Stone GW, Leon MB, Mintz GS. Metaanalysis of randomized studies comparing intravascular ultrasound versus angiographic guidance of percutaneous coronary intervention in pre-drug-eluting stent era. Am J Cardiol 2011; 107: $374-382$.

\section{Supplementary Files}

Please find supplementary file(s);

http://dx.doi.org/10.1253/circj.CJ-20-0369 